\title{
Supply Chain Decision-Making and Coordination considering Anticipated Regret under Price Discount
}

\author{
Jie Jian $\left(\mathbb{D},{ }^{1}\right.$ Huipeng Li, ${ }^{1}$ Nian Zhang $\mathbb{D}^{1},{ }^{1}$ and Jiafu Su $\mathbb{C D}^{2,3}$ \\ ${ }^{1}$ School of Economics and Management, Chongqing University of Posts and Telecommunications, Chongqing, China \\ ${ }^{2}$ Research Center for Economy of Upper Reaches of the Yangtze River, Chongqing Technology and Business University, \\ Chongqing, China \\ ${ }^{3}$ National Research Base of Intelligent Manufacturing Service, Chongqing Technology and Business University, Chongqing, China \\ Correspondence should be addressed to Jiafu Su; jiafu.su@hotmail.com
}

Received 4 April 2020; Revised 3 June 2020; Accepted 24 June 2020; Published 24 July 2020

Guest Editor: Baogui Xin

Copyright (C) 2020 Jie Jian et al. This is an open access article distributed under the Creative Commons Attribution License, which permits unrestricted use, distribution, and reproduction in any medium, provided the original work is properly cited.

\begin{abstract}
The increasing homogeneous product market has made more competition among companies to focus on improving customers' experience. In order to get more competitive advantages, companies often launch discount products to attract consumers. However, stimulated by discount products, the perception of anticipated regret is becoming stronger, which is an inevitable issue in front of companies with price discount strategy. Considering the impact of anticipated regret for discount products, this paper quantitatively describes the utility functions and deduces the demand functions of original price products and discount products. The theoretical analysis and numerical simulation are used to analyze centralized and decentralized models of supply chain for discount products. On its basis, the revenue-sharing contract is designed to optimize the profits of supply chain. This paper finds that the price of products increases first and then decreases with the increase of regret sensitivity coefficient and consumer heterogeneity. When the regret sensitivity coefficient and consumer heterogeneity are lower, companies in the supply chain can adopt the "skimming pricing" strategy in order to obtain more profits. When the regret sensitivity coefficient and consumer heterogeneity increase, companies in the supply chain can adopt "penetrating pricing" strategies to stimulate market demand. For high regret consumers, manufacturers can adopt a "commitment advertising" strategy to promise price and quality, and retailers can adopt a "prestige pricing" strategy to reduce consumer perception of regret. In response to products with higher differences in consumer acceptance, manufacturers can adopt a "differentiated customization" strategy to meet different types of consumer demand and retailers can adopt a "differential pricing" strategy for precise marketing.
\end{abstract}

\section{Introduction}

In the increasingly fierce market competition, companies generally like to implement discount products to acquire more market advantages and attract more customers, such as Amazon Black Friday, Tmall Double Eleven, and other national carnival shopping discount festivals. On the day of Double Eleven in 2019, the entire network generated 1.337 billion parcels, but the return rate after discount products was as high as $30 \%$. The high return cost caused the original meager profits in the supply chain to disappear $[1,2]$. Stimulated by discount products, consumers often expect the current original price products and the future discount products separately. When they realize that their current choices may regret in the future, the negative emotions shown are anticipated regret. The anticipated regret will not only reduce the shopping experience of consumers but also inevitably produce various resource waste and cost losses $[3,4]$. Modern business management has attached great importance to this issue. Like Amazon, AliExpress, and JD. com, many physical malls have promised consumers to enjoy the "right to regret" and implemented offline shopping service with no reason to return and exchange. This measure reduces the risk of consumer anticipated regret and improves corporate reputation [5]. On the other hand, affected by the anticipated regret stimulated by discount products, the product returns will be seriously damaged during the return process. If the supply chain member companies only 
consider their own interests and disregard the decisions of other members, it will lead to supply chain coordination problems [6]. The circulation is particularly tricky, specifically manifested as the profits of the members of the supply chain are not guaranteed, and the profit distribution of the supply chain system is uneven. Revenue-sharing contract is a new profit-based form of profit, and its flexible distribution mechanism is particularly suitable for competitive supply chains whose demand depends on price [7]. Therefore, this article considers the revenue-sharing contract as a coordination mechanism.

The "discount products" has become the most common promotion method for enterprises. This promotion strategy brings a surge in transaction volume for the enterprises but also makes consumers face shopping difficulties during the promotion period when the product is out of stock and codes. Consumers need to make choices about the uncertain future promotion environment or do not understand the real values of original price products and discount products before they buy them. Once uncertainty disappears, consumers regret when they know they could have made better choices. With frequent "discount products" promotion strategy, the anticipated regret from consumers will become more common. This phenomenon greatly affects the promotion decisions of enterprises and makes the supply chain evolve new characteristics and laws. Aiming at the behavior of anticipated regret for discount product, this paper introduces the negative utility formula of anticipated regret to derive the demand functions of the original price products and the discount products. After analyzing the impact of regret sensitivity coefficient and consumer heterogeneity on supply chain members, the revenue-sharing contract was introduced to optimize the supply chain.

In summary, in the face of discount product strategies that companies often adopt, what is the impact of anticipated regret on decision-making for consumers? How to guarantee the profits of the member companies of the supply chain under the consumers' anticipated regret? How should the supply chain choose the appropriate coordination mechanism to achieve the improvement of channel utility? The above has become a new problem in theoretical research and practical management. Revenue-sharing contract is widely used in real life as the most applicable and flexible contract in the supply chain coordination mechanism. The article not only enriches the behavioral economic theory related to consumer anticipated regret but also provides practical basis for companies' discount product strategies.

\section{Literature Review}

Aiming at the impact of anticipated regret on the supply chain stimulated by price discounts, this paper designed the revenue-sharing contract to optimize the supply chain profits. So, the following issues are closely related to discount products supply chain, anticipated regret, and revenuesharing contract. In the following section, the paper reviews studies relevant to discount products supply chain and anticipated regret and highlights the revenue-sharing contract in this situation.
Discount product in supply chain is not only an important topic in everyday society but also receives significant attention in academia. The most representative was that by Monahan [8] who proposed that sellers can attract consumers to increase order volume through discount products, thereby creating more profits. Raju [9] first discovered that the increase of discounts strength will increase the variability of category sales. Davis and Millner [10] used case analysis to demonstrate the impact of different discounts on consumer purchasing behavior, indicating that lower discounts were not favored by consumers. Chan and Lee [11] studied the realization of coordination and incentives for a single coordination model of a single supplier multibuyer supply chain based on discount products of buyer order intervals, finding that the discount products which guaranteed the buyer's overall related coordination costs were reduced. Andrews et al. [12] studied the relationship between marketing and discount products and found that the influence of marketing on sales purchases follows an inverted U-shape relationship under the moderating effect of price discounts. When the discounts are moderate, it is the strongest. Xia [13] studied a supply chain with only one retailer and supplier and addressed how retailers should use their ordering and price decisions to respond to temporary price discounts from their suppliers. Gao et al. [14] established a dualchannel supply chain model, studied the impact of price discounts on the bullwhip effect in e-commerce, and found that price discounts in online retail markets generally amplify the bullwhip effect in the retail supply chain. Shaikh et al. [15] study two different inventory models, namely, (a) inventory model for zero-ending case and (b) inventory model for shortages case. The demand for both models is considered as price and stock dependent, whereas shortages are partially backlogged at a rate with the length of the waiting time to the arrivals of the next lot. Most of the literature about price discount is based on the assumption that consumers complete rationality. In the actual purchase process, consumers are extremely susceptible to discount products and may have anticipated regrets in purchasing decisions.

Anticipated regret is more common and the discount product strategy becomes more frequent, so more research studies focus on anticipated regret. Most of the existing literature analyzed purchasing behavior from the perspective of consumers. Loomes and Sugden [16] proposed and studied the theory of anticipated regret for the first time. Simonson's [17] research found that they would buy products that are guaranteed and free from regrets in future choices after consumers learn that they have made wrong decisions. In contrast, it is less likely to buy more risk products (cheaper products; lesser-known brands). Larrick and Boles [18] found that anticipated regret can make people more risk-seeking than risk-averse. Zeelenberg [19] through empirical research found that anticipated regret promoted risk-aversion and risk-seeking options. Bjälkebring et al. [20] conducted research based on the network day and law and found that anticipated regret was relatively common in daily life decision-making. Anticipated regret was less frequent than predicted regret, so controlling and preventing regrets 
is an important strategy in our daily decision-making. Syam et al. [21] studied the relationship between anticipated regret and product standardization. By establishing a game model, it was found that the higher the anticipated regret coefficient, the more inclined to purchase standardized products, and this relationship will weaken as the number of products increases; Yin and Yu [22] analyzed the impact of anticipated regret on consumers' impulse purchase behavior through a $2 \times 2$ experimental design and found that anticipated regret had a mediation effect in the impact of impulse traits and shopping situations on impulse purchases. Nasiry and Popescu [23] considered two "regrets for action" and "abandon regrets" and analyzed the impact of these two types of anticipated regret on consumers' early purchase decisions. On this basis, Jiang et al. [24] studied the consumer utility formulas with these two types of anticipated regret and analyzed the impact of the sensitivity coefficient of anticipated regret and consumer heterogeneity on the company's new product development strategies. Liu and Zhang [25] analyzed the two-stage dynamic game between retail enterprises and consumers under the symbiotic replacement strategy and single product replacement strategy and found that anticipated regret has a significant impact on consumers' own purchase decisions. Sarangee et al. [26] use anticipated regret theory to develop a model and demonstrate how forward-looking emotions can lead decisionmakers to continue failing NPD projects in business-tobusiness (B2B) markets. The results suggest that anticipated drop regret plays a significant role in commitment to a failing course of action, whereas anticipated keep regret actually reduces commitment. Zhang et al. [27] studied the impact of consumer's anticipated regret on the product innovation supply chain and proposed a continuous replacement product plan. Enterprises should adopt a "moderate innovation strategy" for long-term development. When the attribute exceeds the threshold, the "skimming pricing strategy" is adopted for innovative products; when the product depreciates rapidly, the "skimming pricing strategy" is adopted for incumbent products, and the "penetrating pricing strategy" is adopted for innovative products. The above researches show that anticipated regret has a significant impact on the decisions of supply chain member companies but does not study the impact of anticipated regret caused by "discount products" on supply chain member companies.

In recent years, research on supply chain contract has been quite rich. Starting from Cachon and Lariviere's [28] classic study on supply chain coordination contracts, various contract forms are widely used in a variety of scenarios. Such option contracts were used to solve supply chain financing decisions [29], and wholesale price contracts were used to coordinate retailers' loss-averse supply chains [30]. Revenue-sharing contracts were used to resolve channel conflicts in dual-channel supply chains [31]. Jian et al. [32] examined the contract coordination between manufacturers with peerinduced and distributional fairness concerns and found that there is a revenue-sharing contract parameter in both the peer-induced and distributional fairness concerns of manufacturers. The repurchase contract is suitable for coordination when the retail price is unchanged, but the revenue-sharing contract can also play a good coordination effect under the variable retail price. Compared with the traditional wholesale price contract, the revenue-sharing contract has greater flexibility and practicality. The actual situation of the article is directed to the "price discount promotion" strategy; the most typical feature is that the retail price is variable, so it is more appropriate to choose the revenue-sharing contract.

The existing literature on discount products is mostly based on the assumption of "consumer complete rationality." But in the actual purchase process, consumers are extremely susceptible to price discounts and are not very clear about the actual utility of discounted products. This has led many consumers to regret after purchasing discounted products $[33,34]$. Therefore, it is particularly important to cross-integrate the anticipated regret under discount products with the research on supply chain operations management. Based on this, this paper combines discount products and anticipated regret theory to build three models of centralized decision, decentralized decision, and revenuesharing decision and analyzes the influence of regret sensitivity coefficient and consumer heterogeneity.

\section{Problem Description and Demand Function}

3.1. Problem Description. Suppose that consumer wants to buy a product that has just hit the market early. Based on the past shopping experience, the product will be sold at a discount in the future. At this time, consumers are faced with two choices. If they purchase the current original price products, they may regret the expensive purchase. If they buy future discount products, he may face uncertain factors such as product out of stock and code, which may lead to regret for missing the purchase opportunity. The performance of this kind of consumer anticipating future risks before making decisions is called anticipated regret. This paper uses $p_{n}$ and $p_{d}$ to denote the selling price of the original price product and the discount product per unit, respectively, and $p_{d}=\delta \cdot p_{n}$ ( $\delta$ is the discount level per unit of product).

Considering a supply chain consisting of a manufacturer (represented by the subscript $M$ ) and a retailer (represented by the subscript $R$ ), the original price products existing in the market will be discounted at a certain time in the future. $p_{n}$ represents the price of each unit of original price products. $p_{d}$ represents the discount price products. $p_{d}=\delta \cdot p_{n}(\delta$ is the discount level per unit product). At this time, the consumer's valuation for the original price products is $v$ and obeys the uniform distribution on $[0,1]$. According to consumers' preference for discount products, they are divided into two types: higher preference (type $\theta_{H}$ ) and lower preference (type $\theta_{L}$ ). $\theta_{H}$ and $\theta_{L}$, respectively, indicate acceptance of discounted products by two types of consumers. Set $\theta_{H}=1, \theta_{L}=1-\gamma$. This article uses $\gamma=\theta_{H}-\theta_{L}$ to represent consumer heterogeneity. That is the difference in acceptance of discount products between $\theta_{H}$ and $\theta_{L}$ consumers, because consumers do not know the discount time and discount information of discount products. They are not 
sure of their true preferences before buying, and they do not know the expected utility that can be obtained by purchasing discount products. They only know whether to choose the original price products or the discount products; there are 1/ 2 possibilities to regret; that is, the probability of belonging to both $\theta_{H}$ and $\theta_{L}$ is $1 / 2$. The consumer's expected utility in purchasing discounted product can be expressed as $\left(\left(\theta_{H}+\theta_{L}\right) / 2\right) \nu$. Because consumers have a certain fear of anticipated regret, the anticipated regret generated before the purchase decision will have certain side effects on the consumer's utility. According to research by Jiang et al. [24], the formula for calculating the anticipated regret side effects is as follows:

$$
\text { A.R. }=-\lambda_{i} \cdot \operatorname{prob}\left(U_{f}>U_{c}\right) \cdot\left(U_{f}-U_{c}\right) .
$$

When the consumer chooses to purchase the original price products, the consumer of type $\theta_{H}$ may regret. The net utility of type $\theta_{H}$ consumers who give up buying original price products and buying discount products is $U_{f}=\theta_{H} v-p_{d}=\nu-\delta p_{n}$. The actual net utility of type $\theta_{H}$ consumers who continue to choose to purchase original priced products is $U_{c}=v-p_{n}$.

When the consumer chooses to purchase the discount products, the consumer of type $\theta_{L}$ may regret. The net utility of type $\theta_{L}$ consumers who give up buying discount products and buying original price products is $\bar{U}_{f}=v-p_{n}$. The actual net utility of type $\theta_{L}$ consumers who continue to choose to purchase discount products is $\bar{U}_{c}=\theta_{L} v-p_{d}=$ $(1-\gamma) v-\delta p_{n}$

3.2. Demand Function. According to the above-mentioned analysis, the expressions of the anticipated regret net utility of consumers who purchase of the original products and the discount products are as follows:

$$
\begin{aligned}
U_{n} & =\nu-p_{n}-\frac{\lambda}{2}\left(\left(\nu-\delta p_{n}\right)-\left(\nu-p_{n}\right)\right)=\nu+\frac{p_{n}}{2}(-2+(\delta-1) \lambda), \\
U_{d} & =\frac{\left(\nu-\delta p_{n}\right)+\left((1-\gamma) \nu-\delta p_{n}\right)}{2}-\frac{\lambda}{2}\left(\nu-p_{n}-\left((1-\gamma) \nu-\delta p_{n}\right)\right) \\
& =\frac{\nu}{2}(2-\gamma-\lambda \gamma)+\frac{p_{n}}{2}(\lambda-2 \delta-\lambda \delta) .
\end{aligned}
$$

Similar to the description of Örsdemir et al. and Chiang et al. [35, 36], consumers purchase the original price products when $U_{n}>U_{d}$ and $U_{n}>0$ are satisfied. Consumers purchase discount products when $U_{n}<U_{d}$ and $U_{d}>0$ are satisfied. The critical payment points are $v_{1}=-\left(2 p_{n}(\delta-1) / \gamma\right), \quad v_{2}=\left(p_{n}(2+\lambda-\delta \lambda) / 2\right), \quad$ and $v_{3}=\left(p_{n}(\lambda-\delta(2+\lambda)) /-2+\gamma+\gamma \lambda\right)$ derived from $U_{n}=U_{d}$, $U_{n}=0$, and $U_{d}=0$. Comparing these three critical payment points can obtain the demand function of the original price product and discounted product in the supply chain at this time:

$$
\begin{aligned}
& D_{n}=\int_{U_{n}>U_{d}, U_{n}>0} f(v) \mathrm{d} v= \begin{cases}1-\frac{p_{n}(2+\lambda-\delta \lambda)}{2}, & \text { if } p_{n} \leq 0, \\
1+\frac{2 p_{n}(\delta-1)}{\gamma}, & \text { if } 0 \leq p_{n} \leq \frac{\gamma}{2-2 \delta}, \\
0, & \text { if } p_{n} \geq \frac{\gamma}{2-2 \delta},\end{cases} \\
& D_{d}=\int_{U_{d}>U_{n}, U_{d}>0} f(v) \mathrm{d} v= \begin{cases}0, & \text { if } p_{n} \leq 0, \\
-\frac{2 p_{n}(\delta-1)}{\gamma}-\frac{p_{n}(\lambda-\delta(2+\lambda))}{-2+\gamma+\gamma \lambda}, & \text { if } 0 \leq p_{n} \leq \frac{\gamma}{2-2 \delta}, \\
1-\frac{p_{n}(\lambda-\delta(2+\lambda))}{-2+\gamma+\gamma \lambda}, & \text { if } p_{n} \geq \frac{\gamma}{2-2 \delta} .\end{cases}
\end{aligned}
$$


In the game model, the unprofitable situation of the companies in the supply chain is not considered. The price of the products needs to satisfy the inequality: $0 \leq p_{n} \leq(\gamma / 2-2 \delta)$. At this time, the demand functions of the original price products and the discount products are as follows:

$$
\begin{aligned}
D_{n} & =1+2 p_{n} A, \\
D_{d} & =(-2 A-B) p_{n} .
\end{aligned}
$$

Among them,

$$
\begin{aligned}
A & =\frac{\delta-1}{\gamma}, \\
B & =\frac{\lambda-\delta(2+\lambda)}{\gamma+\gamma \lambda-2} .
\end{aligned}
$$

\section{Models of Different Power Structures}

When manufacturers and retailers play a game in the supply chain, the manufacturers determine the wholesale price of the products, and the retailers determine the retail price of the products. According to the demand function of original price products and discount products, the profit expressions of manufacturers and retailers are as follows:

$$
\begin{aligned}
& \pi_{M}(w)=(w-c)\left(1+2 p_{n} A\right)+(w-c)\left(-2 p_{n} A-p_{n} B\right), \\
& \pi_{R}\left(p_{n}\right)=\left(p_{n}-w\right)\left(1+2 p_{n} A\right)+\left(\delta p_{n}-w\right)\left(-2 p_{n} A-p_{n} B\right) .
\end{aligned}
$$

4.1. Centralized Decision-Making Model. In the case of centralized decision-making situation (CL), manufacturers and retailers form a unified decision-making body. They start from maximizing the overall total profits of the supply chain. The total profit $\pi^{\mathrm{CL}}$ of the entire supply chain under centralized decision-making is as follows:

$$
\begin{aligned}
\pi^{\mathrm{CL}}= & (w-c)\left(1-p_{n} B\right)+\left(p_{n}-w\right)\left(1+2 p_{n} A\right) \\
& +\left(\delta p_{n}-w\right)\left(-2 p_{n} A-p_{n} B\right) .
\end{aligned}
$$

Since $\pi_{\mathrm{ALI}}^{\mathrm{CL} *}>0$ needs to be satisfied, $8 A(-1+\delta)+4 B \delta>0$ and $\left(\partial^{2} \pi^{C L} / \partial p_{n}^{2}\right)=4 A-4 A \delta-2 B \delta<0$ are satisfied. So, the stagnation point is the point where the profit of the unconstrained equilibrium model is maximized. Derivate $p_{n}$ in (8), and obtain the equilibrium expression of retail price $p_{n}$ :

$$
p_{n}^{\mathrm{CL}^{*}}=\frac{1+B c}{-4 A+4 A \delta+2 B \delta} \text {. }
$$

Substituting the above expression, the total profits of the supply chain in the case of centralized decision-making situation can be obtained:

$$
\pi_{\mathrm{ALL}}^{\mathrm{CL}}=\frac{(1+B c)^{2}}{8 A(-1+\delta)+4 B \delta}-c .
$$

4.2. Decentralized Decision-Making Model. Decentralized decision (DL) situation studies traditional manufacturersdominated supply chains, where manufacturers have a dominant role in the pricing process. For example, the vehicle manufacturing company Toyota Motor has completed the preliminary research and development, procurement, manufacturing, logistics (shipping), and $4 \mathrm{~S}$ store management mode on the basis of the original manufacturer. Other upstream and downstream supply chains are supporting enterprises [37]. In the entire supply chain, Toyota car manufacturers have the leading power. Solved by the inverse induction method, the retailers' profits function formula (7) finds the first derivative of $p_{n}$ and gets the response function of product retail price $p_{n}$ to wholesale price $w$ :

$$
p_{n}=\frac{1+B w}{4 A(-1+\delta)+2 B \delta} .
$$

Substituting (11) into (6) gives the manufacturers' profits function expression for $w$ :

$$
\pi_{M}(w)=(w-c)\left(1-\frac{1+B w}{4 A(-1+\delta)+2 B \delta} B\right) .
$$

Since $\pi_{M}^{\mathrm{DL} *}>0$ needs to be satisfied, $2 A(-1+\delta)+B \delta>0$ is derived. $\left(\partial^{2} \pi_{M} / \partial w^{2}\right)=-\left(B^{2} / 2 A(-1+\delta)+B \delta\right)<0$ is proved. The stagnation point is the point where the profit of the unconstrained equilibrium model is maximized. Find the first-order partial derivative of $w$ in (12) to obtain the equilibrium expression of the wholesale price $w$. Replace the reaction function (11) to obtain the equation of equilibrium $p_{n}$ :

$$
\begin{aligned}
w^{\mathrm{DL} *} & =\frac{4 A(\delta-1)+B(B c+2 \delta-1)}{2 B^{2}}, \\
p_{n}^{\mathrm{DL} *} & =\frac{1}{4}\left(\frac{2}{B}+\frac{1+B c}{2 A(\delta-1)+B \delta}\right) .
\end{aligned}
$$

By substituting the above expressions back, we can obtain the demand functions for the original price products and discount products and the profits of manufacturers and retailers in the case of decentralized decision-making situation: 


$$
\begin{aligned}
& D_{n}^{\mathrm{DL} *}=1+\frac{A}{B}+\frac{A+A B c}{4 A(\delta-1)+2 B \delta}, \\
& D_{d}^{\mathrm{DL} *}=\frac{1}{4}(2 A+B)\left(-\frac{2}{B}-\frac{1+B c}{2 A(\delta-1)+B \delta}\right), \\
& \pi_{M}^{\mathrm{DL} *}=\frac{\left(4 A+B+B^{2} c-2(2 A+B) \delta\right)^{2}}{8 B^{2}(2 A(\delta-1)+B \delta)}, \\
& \pi_{R}^{\mathrm{DL} *}=\frac{-48 A^{2}(\delta-1)^{2}-8 A B(\delta-1)(B c+6 \delta-3)+B^{2}\left((1+B c)^{2}-4(B c-3) \delta-12 \delta^{2}\right)}{16 B^{2}(2 A(\delta-1)+B \delta)} .
\end{aligned}
$$

\subsection{Model Analysis}

Proposition 1. $\lambda$ has an inflection point. When $\lambda$ is smaller than the inflection point, $p_{n}$ is positively correlated with $\lambda$, and $w$ is positively correlated with $\lambda$; when $\lambda$ is greater than the inflection point, $p_{n}$ is negatively correlated with $\lambda$, and $w$ is negatively correlated with $\lambda$.

Proposition 1 shows that, as the regret sensitive coefficient increases, the wholesale price and retail price increase first and then decrease. This is because the regret sensitive coefficient is smaller, companies in the supply chain adopt a "skimming pricing" strategy to increase customer perceived value. When the regret sensitive coefficient increases, the reduction of wholesale and retail prices will stimulate more market demands and obtain more supply chain profits. At this time, enterprises should increase the supply of products to meet market demands, increase product promotion efforts, and attract potential customers to expand consumer groups.

Proposition 2. $\gamma$ has an inflection point. When $\gamma$ is smaller than the inflection point, $w$ is positively correlated with $\gamma$; when $\gamma$ is greater than the inflection point, $w$ is negatively correlated with $\gamma$.

Proposition 2 shows that, with the consumer heterogeneity increases, the wholesale price of a product increases first and then decreases. This is because when consumer heterogeneity is lower, supply chain companies gain market profits by increasing product prices. But when consumer heterogeneity is higher, supply chain companies stimulate market demand by reducing the wholesale price of products. At this time, enterprises adopt customized service strategies for consumers with different market preferences and provide professional, one-to-one services.

Proposition 3. Compare and analyze the total profits of the supply chain under different decision-making situations, and find that $\pi_{A L L}^{D L *}<\pi_{A L L}^{C L *}$.

Proposition 3 shows that the total profits of the supply chain in the case of centralized decision-making are always greater than that in the case of decentralized decisionmaking. This is because the centralized situation is based on maximizing the overall total profit of the supply chain.
Centralized decision-making can make manufacturers, retailers, and consumers benefit.

The above proposition proof process is detailed in Appendix. Because derivative result of profits formula is too complicated, the results will be discussed in the numerical analysis section.

\section{Revenue-Sharing Contract}

The supply chain collaboration incentive mechanism based on the revenue-sharing contract is that the manufacturer wholesales the product to the retailer at a lower wholesale price $w$ in the early stage of the sale. After the sales cycle ends, the retailers receive $\varphi(0<\varphi<1)$ proportion of revenue and share $1-\varphi$ proportion of sales revenue to the manufacturers. The profits of the manufacturers and the retailers after being coordinated by the revenue-sharing contract (the coordinated expression is marked with "CO") are as follows:

$$
\begin{aligned}
\pi_{M}^{\mathrm{CO}}(w)= & (w-c)\left(1-p_{n} B\right)+(1-\phi)\left(p_{n}\left(1+2 p_{n} A\right)\right. \\
& \left.-\delta p_{n}\left((2 A+B) p_{n}\right)\right) \\
\pi_{R}^{\mathrm{CO}}\left(p_{n}\right)= & \left(\phi p_{n}-w\right)\left(1+2 p_{n} A\right)+\left(\phi \delta p_{n}-w\right)\left((-2 A-B) p_{n}\right) .
\end{aligned}
$$

The purpose of the revenue-sharing mechanism is to make the optimal retail price under the decentralized decision equal the sales price when the expected profit of the supply chain is maximized; that is, $p_{n}^{\mathrm{CO}}=p_{n}^{\mathrm{CL}}$. The optimal retail price after deriving the retailers' profit (16) from $p_{n}$ can be calculated:

$$
p_{n}^{\mathrm{CO}}=\frac{B w+\varphi}{2(-2 A+2 A \delta+B \delta) \varphi} .
$$

Therefore, as long as (17) is equal to (9), the purpose of incentives is achieved:

$$
w^{\mathrm{CO}}=c \varphi
$$

Take formulas (17) and (18) into formulas (15) and (16), respectively, and the total profits of the manufacturers, retailers, and supply chain after the revenue-sharing contract are as follows: 


$$
\begin{aligned}
& \pi_{M}^{\mathrm{CO}}=\frac{\left((1+B c)^{2}-8 A c(\delta-1)-4 B c \delta\right)(1-\varphi)}{8 A(\delta-1)+4 B \delta}, \\
& \pi_{R}^{\mathrm{CO}}=\frac{\left((1+B c)^{2}-8 A c(\delta-1)-4 B c \delta\right) \varphi}{8 A(\delta-1)+4 B \delta}, \\
& \pi_{\mathrm{ALL}}^{\mathrm{CO}}=\frac{(1+B c)^{2}}{8 A(\delta-1)+4 B \delta}-c .
\end{aligned}
$$

The revenue-sharing contract needs to meet the principle of individual rational people; that is, the profits of the manufacturers and the retailers must not be less than the profits of the noncooperation:

$$
\begin{aligned}
& \pi_{M}^{\mathrm{CO}} \geq \pi_{M}^{\mathrm{DL}}, \\
& \pi_{R}^{\mathrm{CO}} \geq \pi_{R}^{\mathrm{DL}} .
\end{aligned}
$$

From (20) and (21), we can get

$$
\frac{-48 A^{2}(\delta-1)^{2}-8 A B(\delta-1)(B c+6 \delta-3)+B^{2}\left((1+B c)^{2}-4(B c-3) \delta-12 \delta^{2}\right)}{4 B^{2}\left((1+B c)^{2}-8 A c(\delta-1)-4 B c \delta\right)} \leq \varphi \leq 1-\frac{\left(4 A+B+B^{2} c-2(2 A+B) \delta\right)^{2}}{2 B^{2}\left((1+B c)^{2}-8 A c(\delta-1)-4 B c \delta\right)}
$$

Proposition 4. Under the role of the supply chain collaboration mechanism of revenue-sharing contract, the wholesale price should satisfy $w=c \varphi$, and

$$
\frac{-48 A^{2}(\delta-1)^{2}-8 A B(\delta-1)(B c+6 \delta-3)+B^{2}\left((1+B c)^{2}-4(B c-3) \delta-12 \delta^{2}\right)}{4 B^{2}\left((1+B c)^{2}-8 A c(\delta-1)-4 B c \delta\right)} \leq \varphi \leq 1-\frac{\left(4 A+B+B^{2} c-2(2 A+B) \delta\right)^{2}}{2 B^{2}\left((1+B c)^{2}-8 A c(\delta-1)-4 B c \delta\right)}
$$

Proposition 4 shows that when the revenue-sharing contract is introduced for coordination, the revenue-sharing ratio $\varphi$ is an increasing function of the wholesale price $w$. This means that, in the case of decentralized decisionmaking, when the wholesale price agreed between the manufacturers and the retailers is higher, the retailers will enjoy the higher proportion of the $\varphi$ benefit, and the proportion of the $1-\varphi$ benefit to the manufacturers is smaller. Because when the wholesale price is higher, the retailers' purchase costs paid by the retailers at the beginning of the sales season are higher. At the end of the sales season, the smaller the profit realized by the retailers is, the smaller the proportion of profits shared with the manufacturers will be.

\section{Numerical Analysis}

On the basis of theoretical analysis, in order to further visually inspect, this part uses the method of numerical simulation to study the influence of regret sensitivity coefficient and consumer heterogeneity on the pricing decisions of various enterprises in the supply chain. According to the past experience, a cup with cost of two dollars will be discounted by $0.8 \%$ during the promotion period. Suppose that such consumers who prefer discounted cup are $\theta_{H}=1$, and those who prefer original price cup are $\theta_{L}=0.1$. Consumer heterogeneity $\gamma=\theta_{H}-\theta_{L}=0.9$ indicates the difference in the acceptance of discounted cup between these two types of consumers. Consumers' sensitivity to anticipated regret is $\lambda=0.7$. Therefore, the parameters of numerical simulation are set as $\delta=0.8, \gamma=0.9, \lambda=0.7$, and $c=2$.
6.1. Sensitivity Analysis of Regret Sensitive Coefficient. Because anticipated regret affects consumers' acceptance of the cup, it has an important impact on the supply chain. For further visual inspection, the change curves of retail price, wholesale price, and system profits in the supply chain are plotted. It can be shown in Figures 1 and 2.

It can be seen from Figure 1 that the wholesale price (Figure 1(a)) and retail price (Figure 1(b)) of products will decrease with the increase of the regret sensitivity coefficient. And the retail price in the case of centralized decisionmaking is much higher than that of decentralized decisionmaking. This shows anticipated regret expanding the uncertainty of cups' market transactions, so companies can adopt "penetration pricing" strategies to stimulate market demands.

It can be seen from Figure 2 that, with the increased regret sensitivity coefficient, manufacturers' profits (Figure 2(a)), retailers' profits (Figure 2(b)), and the total profits of supply chain (Figure 2(c)) will increase. This shows "penetration pricing" strategy adopted by companies in the supply chain, which has stimulated market demands and achieved a surge in corporate profits. At this time, manufacturers and retailers should especially strengthen the quality and commitment of cups to consumers with high levels of anticipated regret and reduce the level of consumer regret perception. In the case of centralized decision-making, the total profit of the supply chain is much higher than that in the case of decentralized decision-making. The decentralized decision-making situation needs to be coordinated to achieve the optimal decision of the supply chain. 


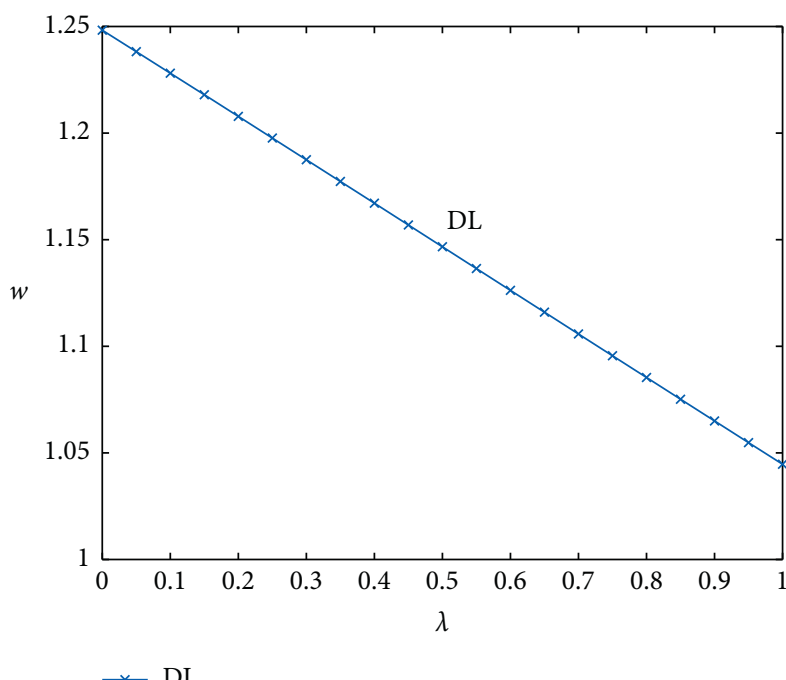

(a)

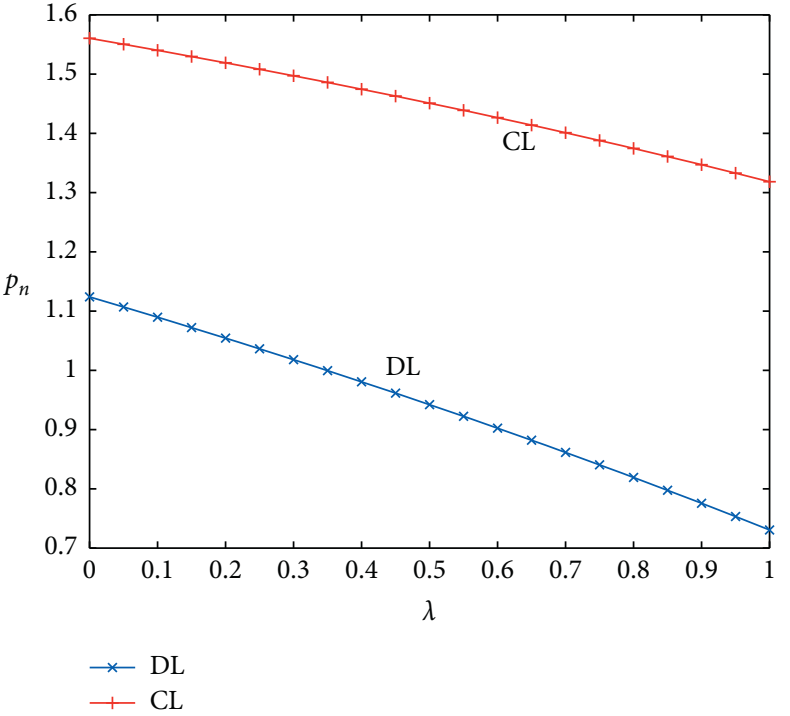

(b)

Figure 1: The impact of regret sensitivity coefficient on wholesale price and retail price: (a) wholesale price and (b) retail prices.

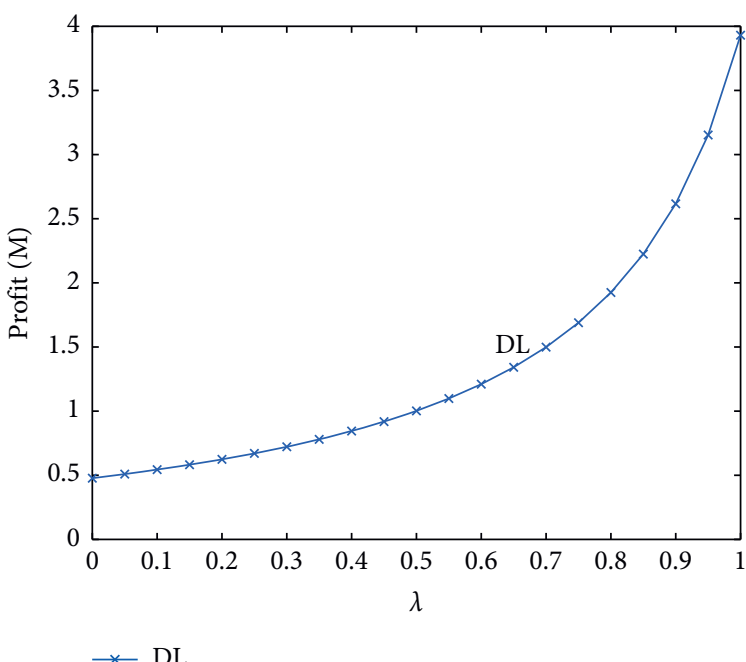

(a)

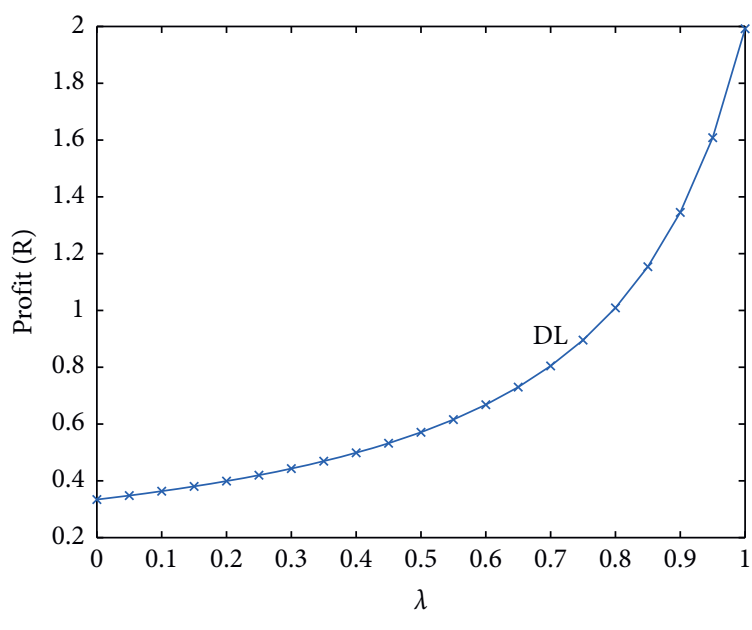

$\rightarrow$ DL

Figure 2: Continued.

(b) 


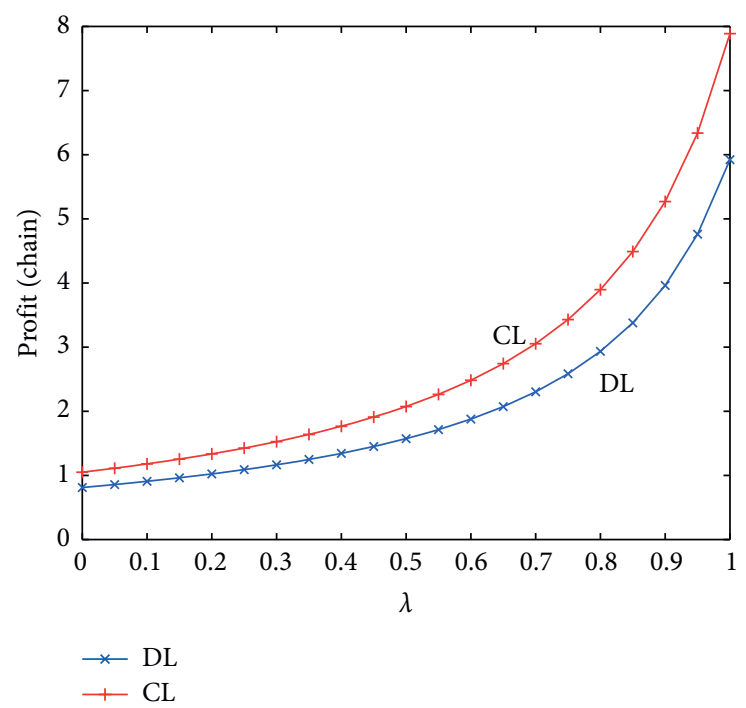

(c)

FIGURE 2: The impact of regret sensitivity coefficient on profits in the supply chain: (a) manufacturers' profits, (b) retailers' profits, and (c) the total profits of supply chain.

6.2. Sensitivity Analysis of Consumer Heterogeneity. Because different types of consumers have different acceptance levels of discount cups, the paper uses $\gamma$ to indicate consumer heterogeneity. This article studies the impact of consumer heterogeneity on cups' prices and the profits of both parties. It can be shown in Figures 3 and 4 .

As can be seen from Figure 3, with consumer heterogeneity increases, the wholesale price (Figure 3(a)) of the product decreases, and the retail price (Figure 3(b)) increases first and then decreases. This is because the heterogeneity of consumers increases the uncertainty of the cup's market. Manufacturers adopt the "low-cost strategy" to obtain more market demands. Retailers first increase the perceived price of customers by increasing the retail price of cups. The "low-price strategy" attracts high-preference $\left(\theta_{H}\right.$ type) consumers. At this time, the supply chain companies can understand the different shopping preferences of consumers through market research and adopt a "commitmentbased advertising strategy" to make quality and price commitments to consumers, reducing the uncertainty of consumer perception. In the centralized decision-making situation, the retail price in this case is higher than the decentralized decision, which shows that market leaders often adopt price competition strategies to obtain supply chain profits. When $\gamma \longrightarrow 0$, the retail price in the case of decentralized decision-making was greater than that in centralized decision-making. Because there are no infinitely small cognitive differences in the product market, this case is not considered in the paper.

As can be seen from Figure 4, as consumer heterogeneity increases, manufacturers' profits (Figure 4(a)) increase first and then decrease and retailers' profits (Figure 4(b)) and the total profits of the supply chain (Figure 4(c)) all increase. This shows that, in the face of consumers with different cup' demands, companies adopt "customized services" and "low- price competition" strategies to stimulate enterprises to obtain more profits. The profit in the case of centralized decision-making is always higher than the profit in the case of decentralized decision-making. Therefore, this paper designs a contract coordination mechanism for decentralized decision-making situations to achieve optimal decisionmaking in the supply chain.

\subsection{Optimal Results and Comparison of Different Decision} Models. First, by comparing the optimal results under the decentralized decision and centralized decision and revenue-sharing mechanism, it can be seen in Table 1 that, compared with decentralized decisions, centralized decision-making reduces the retail price of products and increases the total profit of the supply chain. In other words, decentralized decisions reduce the overall profit of the supply chain and therefore need to be coordinated. After introducing the revenue-sharing contract to coordinate decentralized decision-making, we can know that when the revenue-sharing coefficient satisfies $0.26<\varphi<0.51$ (derived from Proposition 4), there are always $\pi_{M}^{\mathrm{CO}} \geq \pi_{M}^{\mathrm{DL}}, \pi_{R}^{\mathrm{CO}} \geq \pi_{R}^{\mathrm{DL}}$, and $\pi_{\mathrm{ALL}}^{\mathrm{CO}} \geq \pi_{\mathrm{ALL}}^{\mathrm{DL}}$. This proves that the design of the revenuesharing contract increases the profits of both the manufacturer and the retailer, and the overall profit of the supply chain reaches the total profit of the centralized decisionmaking supply chain. The revenue-sharing contract mechanism coordinated the decentralized supply chain, achieved Pareto improvement, and achieved a "win-win" situation in the supply chain.

Figure 5 shows that any value is within the range of $0.26<\varphi<0.51$, manufacturers' profits (Figure 5(a)) under the revenue-sharing mechanism gradually increase, and retailers' profits (Figure 5(b)) gradually decline with $\varphi$ increase. The profits that manufacturers and retailers can distribute in any proportion are greater than the profits 


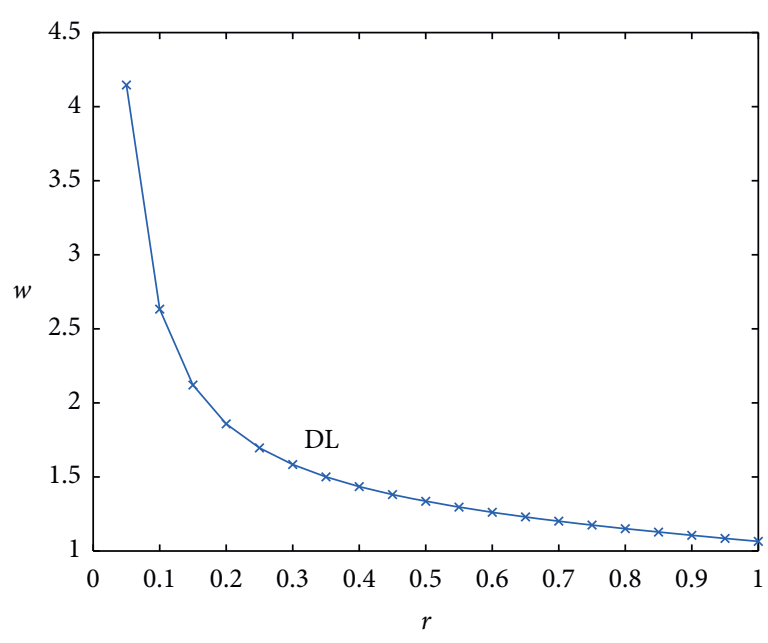

$*$ DL

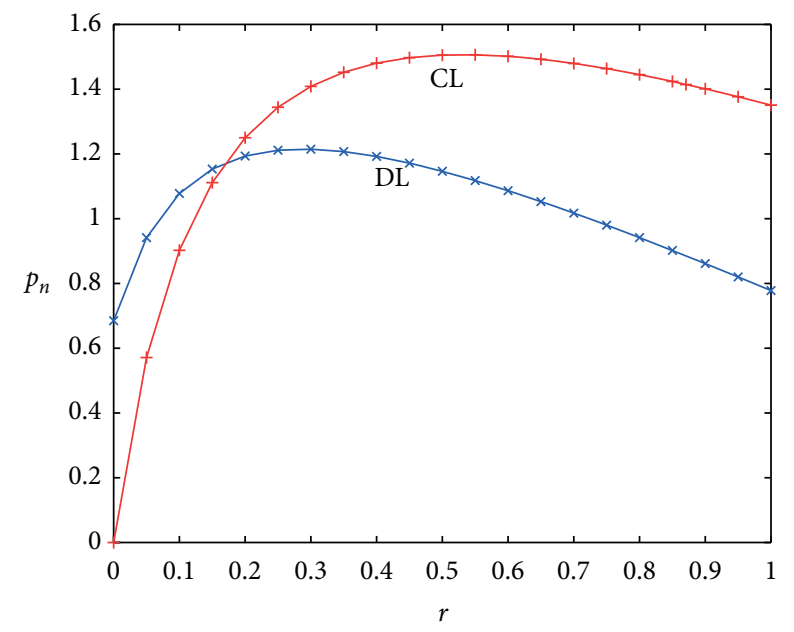

$\rightarrow \mathrm{DL}$

(a)

(b)

FIgURE 3: The impact of consumer heterogeneity on wholesale price and retail price: (a) wholesale price and (b) retail price.

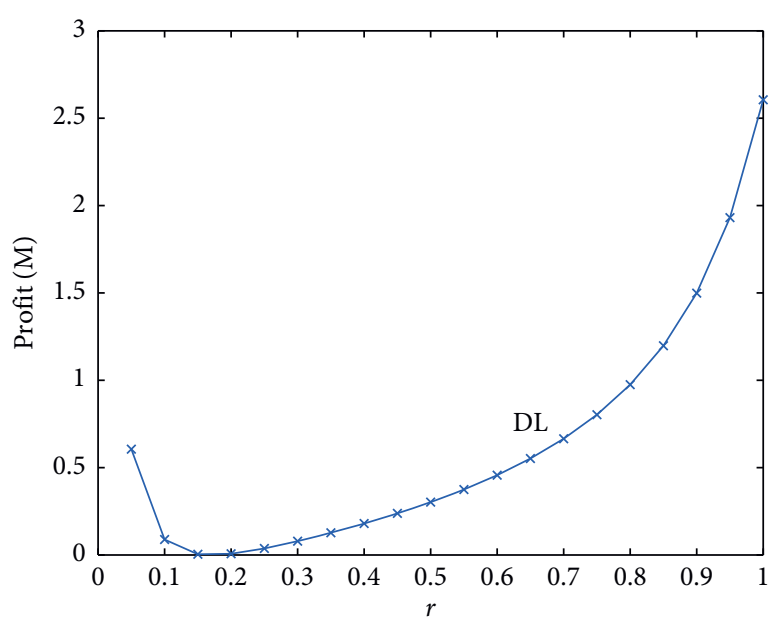
$* \mathrm{DL}$

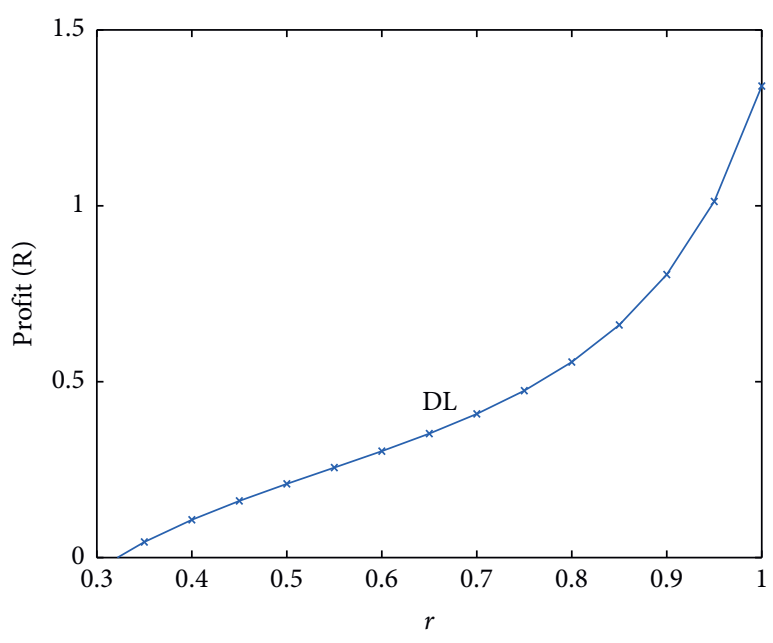

$\star$ DL

(a)

(b)

FIgURE 4: Continued. 


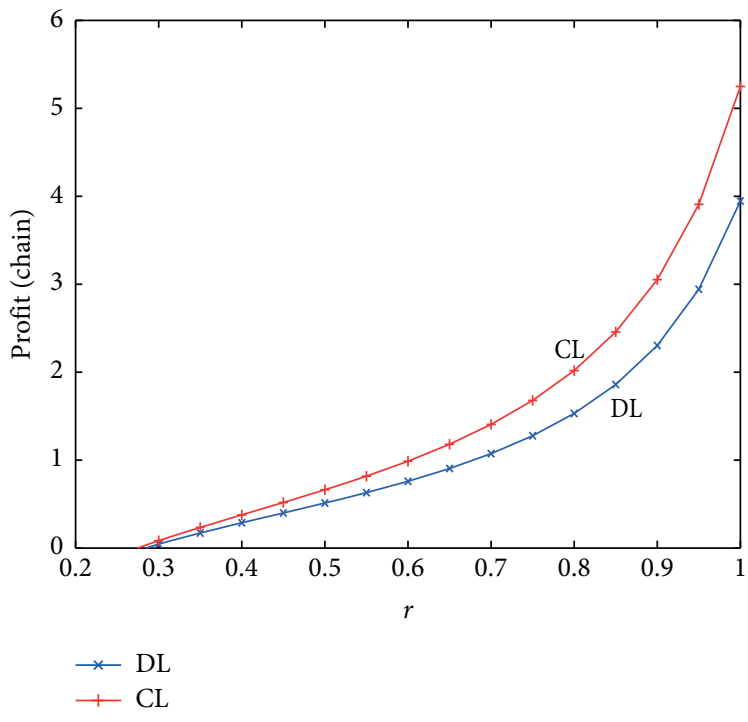

(c)

Figure 4: The impact of consumer heterogeneity on profits in the supply chain: (a) manufacturers' profits, (b) retailers' profits, and (c) the total profits of supply chain.

TABle 1: Profit comparison of members under decentralized decision, centralized decision, and coordination mechanism.

\begin{tabular}{|c|c|c|c|c|}
\hline & $0.26<\varphi<0.51$ & Manufacturer profit & Retailer profit & Total supply chain profit \\
\hline Centralized decision & & & & $\pi_{\mathrm{ALL}}^{\mathrm{DL} *}=3.05$ \\
\hline Decentralized decision & & $\pi_{M}^{\mathrm{CL}^{*}}=1.5$ & $\pi_{R}^{\mathrm{CL}^{*}}=0.8$ & $\pi_{\mathrm{ALL}}^{\mathrm{CL}}=2.3$ \\
\hline \multirow{4}{*}{ Revenue-sharing contract } & $\varphi=0.3$ & $\pi_{M}^{\mathrm{CO}^{*}}=2.14$ & $\pi_{R}^{\mathrm{CO}^{*}}=0.91$ & $\pi_{\mathrm{ALL}}^{\mathrm{CO}}=3.05$ \\
\hline & $\varphi=0.35$ & $\pi_{M}^{\mathrm{CO}^{*}}=1.98$ & $\pi_{R}^{\mathrm{CO}^{*}}=1.07$ & $\pi_{\mathrm{ALL}}^{\mathrm{CO}}=3.05$ \\
\hline & $\varphi=0.4$ & $\pi_{M}^{\mathrm{CO}^{*}}=1.83$ & $\pi_{R}^{\mathrm{CO}^{*}}=1.22$ & $\pi_{\mathrm{ALL}}^{\mathrm{CO}}=3.05$ \\
\hline & $\varphi=0.45$ & $\pi_{M}^{\mathrm{CO}^{*}}=1.68$ & $\pi_{R}^{\mathrm{CO}^{*}}=1.37$ & $\pi_{\mathrm{ALL}}^{\mathrm{CO}}=3.05$ \\
\hline
\end{tabular}

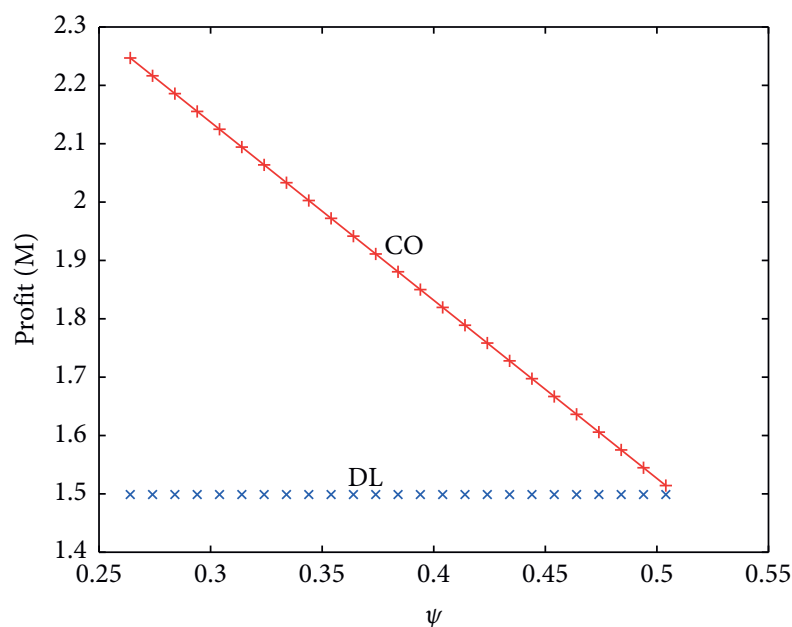

$* \mathrm{DL}$
$+\mathrm{CO}$

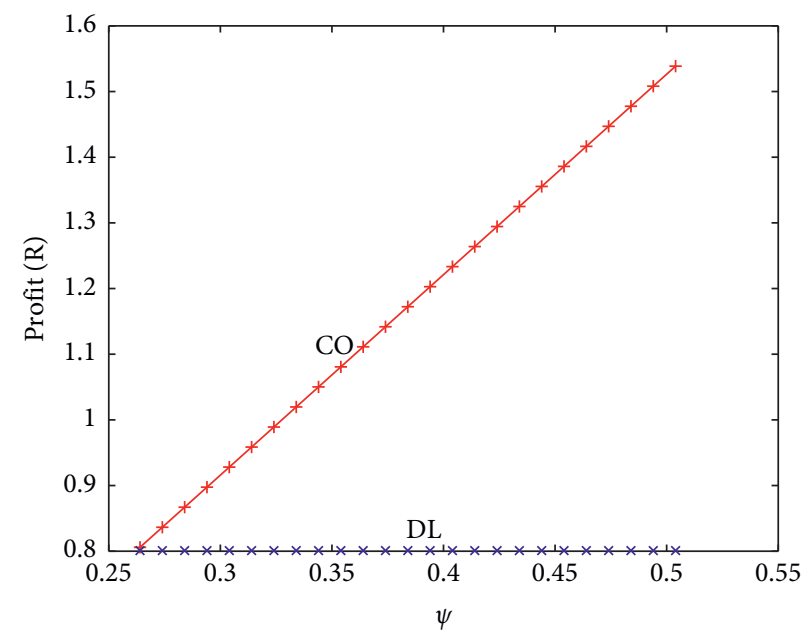

$*$ DL

$+\mathrm{CO}$

(a)

(b)

FIGURE 5: The impact of different contract parameters on supply chain profits under the revenue-sharing mechanism: (a) manufacturers' profits and (b) retailers' profits. 
TABLE 2: Explanation of major symbols and hypothesis.

\begin{tabular}{|c|c|c|}
\hline Variable symbol & Variable description & Assumptions \\
\hline$p_{n}$ & The selling price of the original product per unit & \\
\hline$p_{d}$ & The selling price of the discount product per unit & \\
\hline$w$ & Wholesale price product per unit & \\
\hline$\delta$ & Discount level of product per unit & $0<\delta<1$ \\
\hline$v$ & The consumer valuation of buying original price products & $0<v<1$ \\
\hline$\theta_{H}$ & Consumers who have a higher preference for discount products & $\theta_{H}=1$ \\
\hline$\theta_{L}$ & Consumers who have a lower preference for discount products & $\theta_{L}=1-\gamma$ \\
\hline$\lambda_{i}(i \in\{f, c\})$ & Regret sensitivity coefficient, used to measure how sensitive consumers are to anticipated regret & $0<\lambda<1, \lambda_{c}=\lambda_{f}=\lambda$ \\
\hline $\operatorname{prob}\left(U_{f}>U_{c}\right)$ & The possibility of anticipated regret & $\operatorname{prob}\left(U_{f}>U_{c}\right)=(1 / 2)$ \\
\hline$\gamma$ & Consumer heterogeneity & \\
\hline$U_{f}$ & Net effect of forgotten products & \\
\hline$U_{c}$ & Net effect of chosen products & \\
\hline$c$ & Manufacturer's production costs & \\
\hline
\end{tabular}

when the two parties do not cooperate. When the two parties agree on the parameters of the revenue-sharing contract, the parameters can choose any value in the area. At this time, the profits of both parties are greater than or equal to the profits when they do not cooperate.

\section{Conclusions}

This article considers consumer anticipated regret caused by the "price discount" strategy, constructs centralized decision-making, and decentralizes decision-making models. By examining the effects of regret sensitivity coefficient and consumer heterogeneity on the pricing decisions of supply chain member companies, this paper studies the company's promotion strategies.

As the regret sensitivity coefficient and consumer heterogeneity increase, the price of the product first increases and then decreases. When the regret sensitivity coefficient and consumer heterogeneity are lower, companies in the supply chain can adopt the "skimming pricing" strategy in order to obtain more profits; as the regret sensitivity coefficient and consumer heterogeneity increase, market transactions uncertainty has expanded, so companies in the supply chain can adopt "penetrating pricing" strategies to stimulate market demand. Through numerical simulations, it has been found that low-price strategies cause manufacturers in the supply chain to bear more profit losses. For high regret consumers, manufacturers can adopt a "commitment advertising" strategy to promise price and quality, and retailers can adopt a "prestige pricing" strategy to reduce consumer perception of regret. In response to products with higher differences in consumer acceptance, manufacturers can adopt a "differentiated customization" strategy to meet different types of consumer demand, and retailers can adopt a "differential pricing" strategy for precise marketing.

This article analyzes the impact of anticipated regret under the stimulation of discount products and designs a revenue-sharing contract to achieve a win-win situation for manufacturers and retailers. Although our research addresses some issues, there are still some limitations. For example, this article does not consider the impact on the supply chain when there is a competition between original price products and discount products, nor does it consider the impact of regrets on the retailer-led supply chain at the same time.

\section{Appendix}

\section{A. Sign Convention}

In the model constructed in this paper, the definition and assumptions of specific parameter symbols are shown in Table 2.

\section{B. Proof Process of Propositions}

The first proposition: the expressions of decentralized decision-making (DL) $w$ and $p_{n}$, respectively, find the firstorder partial derivative of $\lambda$ and get

$$
\begin{aligned}
& \frac{\partial w^{\mathrm{DL}}}{\partial \lambda}=\frac{(-2+\gamma+(2+\gamma) \delta)\left(-16(-1+\delta)^{2}+\gamma(8+7 \lambda+\delta(-14-13 \lambda+\delta(4+6 \lambda)))\right)}{2 \gamma(-\lambda+\delta(2+\lambda))^{3}}, \\
& \frac{\partial p_{n}^{\mathrm{DL}}}{\partial \lambda}=\frac{-2+\gamma+(2+\gamma) \delta}{4}\left(\frac{\gamma\left(2 c(-1+\delta)^{2}-\gamma \delta\right)}{\left(-4(-1+\delta)^{2}+\gamma(2(1+\lambda)+\delta(-4+(-3+\delta) \lambda))\right)^{2}}-\frac{2}{(\lambda-\delta(2+\lambda))^{2}}\right) .
\end{aligned}
$$

It can be seen that $\lambda$ has an inflection point. When $\lambda$ is smaller than the inflection point, $\left(\partial w^{\mathrm{DL}} / \partial \lambda\right)>0$, $\left(\partial p_{n}^{\mathrm{DL}} /\right.$ $\partial \lambda)>0$. When $\lambda$ is greater than the inflection point, $\left(\partial w^{\mathrm{DL}} / \partial \lambda\right)>0,\left(\partial p_{n}^{\mathrm{DL}} / \partial \lambda\right)>0$. Therefore, Proposition 1 is 
proved. The specific proof process of the centralized decision case $(\mathrm{CL})$ is similar to the decentralized decision case (DL) and is omitted here for the sake of space.

The second proposition: in the case of decentralized decision-making, the expression $w$ finds the first partial derivative of $\gamma$ :

$$
\frac{\partial w^{\mathrm{DL}}}{\partial \gamma}=\frac{-16(-1+\delta)^{2}+\gamma^{2}(1+\lambda)(4+3 \lambda+\delta(-6+(-5+2 \delta) \lambda))}{2(2 \gamma \delta+\gamma(-1+\delta) \lambda)^{2}} .
$$

It can be seen that $\gamma$ has an inflection point. When $\gamma$ is smaller than the inflection point, $\left(\partial p_{n}^{\mathrm{DL}} / \partial \gamma\right)>0$. When $\gamma$ is greater than the inflection point, $\left(\partial p_{n}^{\mathrm{DL}} / \partial \gamma\right)>0$. Therefore, Proposition 2 is proved. The specific proof process of the centralized decision case (CL) is similar to the decentralized decision case (DL) and is omitted here for the sake of space.

The third proposition: subtract the total profit of the supply chain in different situations:

$$
\pi_{A L L}^{D L *}-\pi_{\mathrm{ALL}}^{\mathrm{CL} *}=-\frac{\left(4 A+B+B^{2} c-2(2 A+B) \delta\right)^{2}}{16 B^{2}(-2 A+2 A \delta+B \delta)}<0 .
$$

Since $-2 A+2 A \delta+B \delta>0, \quad \pi_{\mathrm{ALL}}^{\mathrm{DL} *}-\pi_{\mathrm{ALL}}^{\mathrm{CL} *}<0$ is always true, so Proposition 3 is proved.

\section{Data Availability}

The data used to support the findings of this study are included within the article.

\section{Conflicts of Interest}

The authors declare that they have no conflicts of interest.

\section{Acknowledgments}

The authors are grateful to the support of Team of Trade Circulation Funding Project (CJSYTD201701), Chongqing Municipal Education Commission humanities and Social Sciences Research Project (17SKG065), E-commerce and modern logistics Chongqing university municipal key laboratory open fund project (ECML202002), Chongqing Social Science Planning Doctoral Program, China(2018BS71), and the Humanities \& Social Science Foundation of Chongqing Municipal Education Commission, China(18SKGH045).

\section{References}

[1] Y. Su and W. Sun, "Analyzing a closed-loop supply chain considering environmental pollution using the NSGA-II," IEEE Transactions on Fuzzy Systems, vol. 27, no. 5, pp. 1066-1074, 2019.

[2] J. Jian, Y. Guo, L. Jiang, Y. An, and J. Su, "A multi-objective optimization model for green supply chain considering environmental benefits," Sustainability, vol. 11, no. 21, p. 5911, 2019.

[3] G. Y. Ke and J. H. Bookbinder, "Coordinating the discount policies for retailer, wholesaler, and less-than-truckload carrier under price-sensitive demand: a tri-level optimization approach," International Journal of Production Economics, vol. 196, no. 1, pp. 82-100, 2018.

[4] M. Mourali, Z. Yang, F. Pons, and D. Hassay, "Consumer power and choice deferral: the role of anticipated regret," International Journal of Research in Marketing, vol. 35, no. 1, pp. 81-99, 2018.

[5] J. Su, Q. Bai, S. Sindakis, X. Zhang, and T. Yang, "Vulnerability of multinational corporation knowledge network facing resource loss," Management Decision, 2020, In press.

[6] R. Levi, G. Perakis, C. Shi, and W. Sun, "Strategic capacity planning problems in revenue-sharing joint ventures," Production and Operations Management, vol. 29, no. 3, pp. 1-24, 2020.

[7] J. A. Niederhoff and P. Kouvelis, "Effective and necessary: individual supplier behavior in revenue sharing and wholesale contracts," European Journal of Operational Research, vol. 277, no. 3, pp. 1061-1070, 2019.

[8] J. P Monahan, "A quantity discount pricing model to increase vendor profits," Management Science, vol. 32, no. 11, pp. 1513-1517, 1986.

[9] J. S. Raju, "The effect of price promotions on variability in product category sales," Marketing Science, vol. 11, no. 3, pp. 207-220, 1992.

[10] D. D. Davis and E. L. Millner, "Rebates, matches, and consumer behavior," Southern Economic Journal, vol. 72, no. 2, pp. 410-421, 2005.

[11] C. K. Chan and Y. C. E. Lee, "A co-ordination model combining incentive scheme and co-ordination policy for a singlevendor-multi-buyer supply chain," International Journal of Production Economics, vol. 135, no. 1, pp. 136-143, 2012.

[12] M. Andrews, X. Luo, Z. Fang, and J. Aspara, "Cause marketing effectiveness and the moderating role of price discounts," Journal of Marketing, vol. 78, no. 6, pp. 120-142, 2014.

[13] Y. Xia, "Responding to supplier temporary price discounts in a supply chain through ordering and pricing decisions," International Journal of Production Research, vol. 54, no. 7, pp. 1938-1950, 2016.

[14] D. Gao, N. Wang, Z. He, and T. Jia, "The bullwhip effect in an online retail supply chain: a perspective of price-sensitive demand based on the price discount in E-commerce," IEEE Transactions on Engineering Management, vol. 64, no. 2, pp. 134-148, 2017.

[15] A. A. Shaikh, M. A.-A. Khan, G. C. Panda, and I. Konstantaras, "Price discount facility in an EOQ model for deteriorating items with stock-dependent demand and partial backlogging," International Transactions in Operational Research, vol. 26, no. 4, pp. 1365-1395, 2019.

[16] G. Loomes and R. Sugden, "Regret theory: an alternative theory of rational choice under uncertainty," The Economic Journal, vol. 92, no. 368, pp. 805-824, 1982.

[17] I. Simonson, "The influence of anticipating regret and responsibility on purchase decisions," Journal of Consumer Research, vol. 19, no. 1, pp. 105-118, 1992.

[18] R. P. Larrick and T. L. Boles, "Avoiding regret in decisions with feedback: a negotiation example," Organizational Behavior and Human Decision Processes, vol. 63, no. 1, pp. 87-97, 1995.

[19] M. Zeelenberg, "Anticipated regret, expected feedback and behavioral decision making," Journal of Behavioral Decision Making, vol. 12, no. 2, pp. 93-106, 1999.

[20] P. Bjälkebring, D. Västfjäll, O. Svenson, and P. Slovic, "Regulation of experienced and anticipated regret in daily decision making," Emotion, vol. 16, no. 3, pp. 381-386, 2015.

[21] N. Syam, P. Krishnamurthy, and J. D. Hess, "That's what I thought I wanted? miswanting and regret for a standard good 
in a mass-customized world," Marketing Science, vol. 27, no. 3, pp. 379-397, 2008.

[22] C. Yin and H. Yu, "Research on the impact of expected regret on consumer impulse buying behavior," Business Review, vol. 21, no. 12, pp. 71-79, 2009.

[23] J. Nasiry and I. Popescu, "Advance selling when consumers regret," Management Science, vol. 58, no. 6, pp. 1160-1177, 2012.

[24] B. J. Jiang, C. Narasimhan, and O. Turut, "Anticipated regret and product innovation," Social Science Electronic Publishing, vol. 1, no. 1, pp. 1-32, 2015.

[25] W. Q. Liu and J. J. Zhang, "Research on price discrimination strategy considering consumers' expectations of regret," Chinese Journal of Management Science, vol. 26, no. 5, pp. 1-8, 2018.

[26] K. R. Sarangee, J. B. Schmidt, and R. J. Calantone, “Anticipated regret and escalation of commitment to failing, new product development projects in business markets," Industrial Marketing Management, vol. 76, pp. 157-168, 2019.

[27] N. Zhang, S. Y. Li, L. Jiang, and J. Jian, "Research on the leadership structure of innovative product supply chain considering expected regret," Industrial Engineering Journal, vol. 22, no. 5, pp. 32-42, 2019.

[28] G. P. Cachon and M. A. Lariviere, "Supply chain coordination with revenue-sharing contracts: strengths and limitations," Management Science, vol. 51, no. 1, pp. 30-44, 2005.

[29] L. H. Zhang, Y. J. Wu, and Y. J. Li, "Research on optimal retailer financing strategy based on option contract," Management Review, vol. 26, no. 10, pp. 197-208, 2014.

[30] P. Zhang, J. Zhang, and J. Ma, "Supply chain contract and coordination considering expected loss aversion," Management Review, vol. 27, no. 4, pp. 177-186, 2015.

[31] L. Q. Zhao, J. W. Xu, and J. M. Wang, "Contract design of dual channel conflict and coordination in supply chain based on electronic market," China Management Science, vol. 22, no. 5, pp. 61-68, 2014.

[32] J. Jian, Y. Zhang, L. Jiang, and J. Su, "Coordination of supply chains with competing manufacturers considering fairness concerns," Complexity, vol. 2020, Article ID 4372603, 15 pages, 2020.

[33] B. Zeng, X. Ma, and J. Shi, "Modeling method of the grey GM $(1,1)$ model with interval grey action quantity and its application," Complexity, vol. 2020, Article ID 6514236, 10 pages, 2020.

[34] J. Su, C. Li, Q. Zeng, J. Yang, and J. Zhang, "A green closedloop supply chain coordination mechanism based on thirdparty recycling," Sustainability, vol. 11, no. 19, p. 5335, 2019.

[35] W.-y. K. Chiang, D. Chhajed, and J. D. Hess, "Direct marketing, indirect profits: a strategic analysis of dual-channel supply-chain design," Management Science, vol. 49, no. 1, pp. 1-20, 2003.

[36] A. Örsdemir, E. Kemahlığlu-Ziya, and A. K. Parlaktürk, "Competitive quality choice and remanufacturing," Production and Operations Management, vol. 23, no. 1, pp. 48-64, 2014.

[37] S. Jiafu, Y. Yang, and X. Zhang, "Knowledge transfer efficiency measurement with application for open innovation networks," International Journal of Technology Management, vol. 81, no. 1-2, pp. 118-142, 2019. 